\title{
Correction: Effect of Door-to-Door Screening and Awareness Generation Activities in the Catchment Areas of Vision Centers on Service Use: Protocol for a Randomized Experimental Study
}

Shalinder Sabherwal ${ }^{1}$, MPH, MD; Anand Chinnakaran ${ }^{1}$, MSW; Ishaana Sood ${ }^{1}$, BSc; Gaurav K Garg ${ }^{2}$; Birendra P Singh $^{3}$; Rajan Shukla ${ }^{4}$, MPH, PhD; Priya A Reddy ${ }^{5}$; Suzanne Gilbert ${ }^{6}, \mathrm{MPH}, \mathrm{PhD}$; Ken Bassett ${ }^{7}$, MD, PhD; Gudlavalleti V S Murthy ${ }^{4}, \mathrm{MSc}, \mathrm{MD}$; Operational Research Capacity Building Study Group ${ }^{8}$

\footnotetext{
${ }^{1}$ Department of Community Ophthalmology and Public Health Research, Dr Shroff's Charity Eye Hospital, New Delhi, India

${ }^{2}$ Department of Projects and Marketing, Dr Shroff's Charity Eye Hospital, New Delhi, India

${ }^{3}$ Department of Optometry, Dr Shroff's Charity Eye Hospital, New Delhi, India

${ }^{4}$ Indian Institute of Public Health, Hyderabad, India

${ }^{5}$ School of Medicine, Dentistry and Biomedical Sciences, Queen's University, Belfast, United Kingdom

${ }^{6}$ Seva Foundation, Berkeley, CA, United States

${ }^{7}$ University of British Columbia, Vancouver, BC, Canada

${ }^{8}$ See Authors' Contributions,
}

\section{Corresponding Author:}

Shalinder Sabherwal, MPH, MD

Department of Community Ophthalmology and Public Health Research

Dr Shroff's Charity Eye Hospital

5027, Kedarnath Lane

Daryaganj

New Delhi, 110002

India

Phone: 919910305208

Email: Shalinder.sabherwal@sceh.net

\section{Related Article:}

Correction of: https://www.researchprotocols.org/2021/11/e31951/

(JMIR Res Protoc 2022;11(1):e35824) doi: 10.2196/35824

In "Effect of Door-to-Door Screening and Awareness Generation Activities in the Catchment Areas of Vision Centers on Service Use: Protocol for a Randomized Experimental Study" (JMIR Res Protoc 2021;10(11):e31951) one error was noted.

The following text was originally published in the Acknowledgments section of the paper. This text has now been moved instead to the Authors' Contributions section:

The Operational Research Capacity Building Group consists of the following authors, who contributed equally to the paper: Gudlavalleti VS Murthy, Rajan Shukla, Samiksha Singh, Shailaja Tetali, Suresh K Rathi, Hemant Mahajan, Melissa G Lewis, Hira Pant, Tripura Batchu, Anirudh G Gaurang, Suzanne Gilbert, Ken Bassett, Priya A Reddy, Parami
Dhakhwa, Ram P Kandel, Kuldeep Singh, and Prasanna Sharma.

Accordingly, the affiliation for the group author Operational Research Capacity Building Group has been changed from:

See Acknowledgments to:

\section{See Authors' Contributions}

The corrections will appear in the online version of the paper on the JMIR Publications website on January 18, 2022, with the publication of this correction notice. Because this was made after submission to PubMed, PubMed Central, and other full-text repositories, the corrected article has also been resubmitted to those repositories. 
This is a non-peer-reviewed article. Submitted 04.01.22; accepted 12.01.22; published 18.01.22.

Please cite as:

Sabherwal S, Chinnakaran A, Sood I, Garg GK, Singh BP, Shukla R, Reddy PA, Gilbert S, Bassett K, Murthy GVS, Operational Research Capacity Building Study Group

Correction: Effect of Door-to-Door Screening and Awareness Generation Activities in the Catchment Areas of Vision Centers on Service Use: Protocol for a Randomized Experimental Study

JMIR Res Protoc 2022;11(1):e35824

URL: https://www.researchprotocols.org/2022/1/e35824

doi: $\underline{10.2196 / 35824}$

PMID:

(C) Shalinder Sabherwal, Anand Chinnakaran, Ishaana Sood, Gaurav K Garg, Birendra P Singh, Rajan Shukla, Priya A Reddy, Suzanne Gilbert, Ken Bassett, Gudlavalleti V S Murthy, Operational Research Capacity Building Study Group. Originally published in JMIR Research Protocols (https://www.researchprotocols.org), 18.01.2022. This is an open-access article distributed under the terms of the Creative Commons Attribution License (https://creativecommons.org/licenses/by/4.0/), which permits unrestricted use, distribution, and reproduction in any medium, provided the original work, first published in JMIR Research Protocols, is properly cited. The complete bibliographic information, a link to the original publication on https://www.researchprotocols.org, as well as this copyright and license information must be included. 